\title{
Intermetallic Compound Layer Growth at the Interface between Sn-Ag and ENImAg Surface Finish
}

\author{
Rabiatul Adawiyah Mohamed Anuar', Mohamad Shahrom Hamidin ${ }^{2}$, Saliza Azlina Osman ${ }^{3 *}$ and $^{1}$ \\ Mohamad Hilmi Othman ${ }^{4}$ \\ ${ }^{1,2,3,4}$ Faculty of Mechanical and Manufacturing Engineering, Universiti Tun Hussein Onn Malaysia, 86400 Parit \\ Raja, Johor, Malaysia \\ ${ }^{1}$ rabiatuladda90@gmail.com \\ ${ }^{2}$ mohamadshahrom95@gmail.com \\ 3salizaz@uthm.edu.my \\ ${ }^{4}$ hilmi@uthm.edu.my
}

\begin{abstract}
The growth of an intermetallic compound (IMC) can influence the behavior of solder joints. In this study, the different percentages of $\mathrm{Ag}$ in $\mathrm{Sn}-\mathrm{xAg}$ (value $\mathrm{x}=2.5$ and 3.5 wt.\%) solder alloy were involved along with ENImAg surface finish to reveal the solder joints reliability in term of IMC thickness, morphology and strength of solder joint under reflow and multiple reflows. The characterization and samples analysis were examined by OM and SEM/EDX. The observation revealed that the IMC of $\mathrm{Sn}-\mathrm{xAg} / \mathrm{ENImAg}$ which were formed on the interface were $\mathrm{Ni}_{3} \mathrm{Sn}_{4}$ and NiSn-P layer after multiple reflows soldering. The kinetic growth of each IMC was observed. It revealed that the layer of IMC was thicker as the reflow increased and became thinner with higher mass percentages of Ag. For solder joint strength, the fracture surface with ductile characteristics at the $\mathrm{Sn}-\mathrm{Ag} / \mathrm{ENImAg}$ interface, which indicated that an increase of $\mathrm{Ag}$ wt.\% in the solder, increases the strength of the solder joint. Upon the revelation of these observations, the reliability of the solder joint is related to the reflow condition and mass percentages of the element in the solder alloy.
\end{abstract}

Key words : ENImAg, intermetallic compound, multiple reflow, Sn-Ag.

\section{INTRODUCTION}

Low temperatures of solders are needed for electronic supportability in terms of electrical conductivity [1]. It offers a variety of technical benefits such as wettability [2] spreading capabilities, ductility, fatigue resistance [3], [4] mechanical strength as well as reduces the risk of thermal shock [5]. For example, the traditional lead-based $(\mathrm{Sn}-\mathrm{Pb})$ solders commonly used as the interconnection solder for a relatively long time due to low melting temperature and cost. Besides, $\mathrm{Sn}-\mathrm{Pb}$ has a different combination of chemical, thermal, physical, and mechanical properties [4], [6] in order to provide good performance of solder joints. These alloys have a low melting temperature at $180 \square$, which is $63 \mathrm{Sn}-37 \mathrm{~Pb}$ and $60 \mathrm{Sn}-40 \mathrm{~Pb}$ at the eutectic composition and near eutectic temperature, respectively.

Many manufacturer's concern about the disadvantages of $\mathrm{Sn}-\mathrm{Pb}$, which is causing the environmental and human health affected due to the toxicity of $\mathrm{Pb}$ [7]-[12]. Due to these problems, lead-free candidate alloys such as the Sn-Ag are believed can replace the $\mathrm{Sn}-\mathrm{Pb}$ solders. The binary of $\mathrm{Sn}-\mathrm{Ag}$ system shows better electrical properties and mechanical properties such as creep resistance, ductility and thermal resistance [13], [14]. Compared with Sn-Pb solders, Sn-Ag has several problems which are high melting point (221 $\square$ ), oxidation resistance, poor wettability and reliability of solder joints [10], [15], [16]. Sharif and Chan [16] found that the dissolution of $\mathrm{Sn}-\mathrm{Ag} / \mathrm{Cu}$ is higher than $\mathrm{SnPb} / \mathrm{Cu}$ and the number of IMCs at the interface is thicker than $\mathrm{Sn}-\mathrm{Pb} / \mathrm{Cu}$. If the melting temperature of the solder is high, the solder needs a higher soldering temperature. Hence, it will be leading to rapid IMC growth and affected the solder joints reliability.

Generally, the IMC formation happened at the interface between the substrate and solder. The Cu board is commonly used as metallization. Then, $\mathrm{Sn}$ and $\mathrm{Cu}$ reacted with each other to form the IMCs layer which is $\mathrm{Cu}_{6} \mathrm{Sn}_{5}$ and $\mathrm{Cu}_{3} \mathrm{Sn}$ phases. From the previous experiments, $\mathrm{Cu}_{6} \mathrm{Sn}_{5}$ phase formed first at the solder/Cu interface, followed by the formation of $\mathrm{Cu}_{3} \mathrm{Sn}$ phase between $\mathrm{Cu}_{6} \mathrm{Sn}_{5} / \mathrm{Cu}$ interfaces after a given period of soldering. However, many technical issues arise from the $\mathrm{Cu}$-Sn IMCs, which is $\mathrm{Sn}$-based lead-free solders were not compatible with $\mathrm{Cu}$-based metallization due to IMCs grow rapidly at the interface [17], [18]. The thickening layer of IMC can lead the whole device failure. As alternatives, $\mathrm{Ni}$-based or electroless nickel (EN) is frequently used as a diffusion barrier layer between the solder and $\mathrm{Cu}$ substrate with a view to lessen the rapid reaction between them. 
EN is a deposition process which is to deposit nickel on a substrate including copper, aluminum, titanium, mild steels, stainless steel, hardened steel, brass and die-cast [19]-[22]. This deposition is known as an auto-catalytic reaction or chemical reduction process, which does not use electrical energy. The deposition process is depending on the existence of a reducing agent such as sodium hypophosphite, where it responds with the ions (example, nickel sulphate) to deposit onto the metal substrate. Besides, the characteristic of EN has relied on phosphorus $(\mathrm{P})$ contents which are classified as low-P, medium-P and high-P with the percentages of 3-5 wt. $\%, 6-9$ wt. $\%$ and 10-14 wt.\%, respectively [22]-[25]. Referring to studies, they have mentioned that the as-deposited plating is a microcrystalline or crystalline phase and amorphous at low and high phosphorus levels, while a mixture of amorphous + microcrystalline happens when the level of $\mathrm{P}$ content is medium. Each level of $\mathrm{P}$ content has different mechanical properties. For example, low-P content has excellent wear resistance and corrosion resistance. Meanwhile, medium-P content has good protection of corrosion and abrasion resistance for most applications [20].

In the period of the soldering process, the Ni layer will be reacted with solder or $\mathrm{Sn}$ to form a phase of $\mathrm{Ni}-\mathrm{Sn}$. This reaction showed that the $\mathrm{Ni}$ diffused into molten solder through the narrow channels present in between $\mathrm{Ni}_{3} \mathrm{Sn}_{4}$ layer [18]. Also, a P-rich layer or known as $\mathrm{Ni}_{3} \mathrm{P}$ forms between $\mathrm{Ni}-\mathrm{Sn}$ and nickel layers. In the Ni-Sn binary system, there are three stable formation which are $\mathrm{Ni}_{3} \mathrm{Sn}_{4}, \mathrm{Ni}_{3} \mathrm{Sn}_{2}$, and $\mathrm{Ni}_{3} \mathrm{Sn}$. According to previous researchers, after the soldering of $\mathrm{Sn}-\mathrm{Pb}$ [26], [27], Sn-Ag [28]-[30], and Sn-Bi [31]-[33] on $\mathrm{Cu} / \mathrm{Ni}$ substrate, $\mathrm{Ni}_{3} \mathrm{Sn}_{4}$ was formed at the interface. While the $\mathrm{Ni}_{3} \mathrm{Sn}_{2}$ and $\mathrm{Ni}_{3} \mathrm{Sn}$ IMCs is formed at the interface when it exposed to longer reaction time and at higher temperatures. Besides the Ni-Sn system, there are other types of stable IMCs of interface known as $\mathrm{Cu}-\mathrm{Ni}-\mathrm{Sn}$ phase which is $(\mathrm{Cu}, \mathrm{Ni})_{6} \mathrm{Sn}_{5}$ and $(\mathrm{Ni}, \mathrm{Cu})_{3} \mathrm{Sn}_{4}$. These formations commonly happened when having three elements in the solder content, for example, Sn-Ag-Cu (SAC) solder alloy [34]-[36].

Many failure modes of the IMC are related to the type of solder [18], [37] including element wt.\% in the solder, and surface finish used [26], [38]. Several researchers have investigated the reaction between $\mathrm{Sn}-\mathrm{Ag}$ and $\mathrm{Cu} /$ surface finish such as Ni-P [29], [39], Ni-W-P [30], ENIG [29], [30], $\operatorname{ImAg}$ [40] and OSP [41]. From the observation, the de-wetting of surface finish is associated with the thickness of IMC. This is because each surface finish produced different IMC growth during soldering. Besides, temperature and soldering conditions such as solid diffusion during multiple reflows [16], [26] or isothermal aging also influence the reaction of IMC growth [42], [43].

However, research work on the study of IMC formation and growth of $\mathrm{Sn}-\mathrm{xAg}(\mathrm{x}=2.5$ and $\mathrm{x}=3.5)$ solder alloy with electroless nickel immersion silver $(\mathrm{ENImAg})$ surface finish has not been reported in the literature. ENImAg surface finish was introduced as an alternative to the ENIG surface finish [36], [44]. This surface finish can protect the exposed $\mathrm{Cu}$ plate and also provide a solderable surface finish during soldering. Therefore, the growth of IMC at the interface between $\mathrm{Sn-xAg}$ and the ENImAg surface finish is investigated. In addition, the effects of multiple reflows (4 times) were conducted on $\mathrm{SnAg} / \mathrm{ENImAg}$ to reveal the reliability of solder joints.

\section{MATERIALS AND METHODS}

The $\mathrm{Cu}$ plates consisted of $\mathrm{Cu}$ coated FR4 (flame resist-4) with a dimension of $7.5 \mathrm{~mm} \times 5.0 \mathrm{~mm} \times 0.15 \mathrm{~mm}$ were used as substrates. It has undergone a pre-treatment process before electroless coating. The ENImAg/Cu was ground, cleaned with alkaline water (soap), and treated in a $10 \mathrm{~g}$ sodium hydroxide, $5 \mathrm{~g}$ sodium persulphate and $30 \mathrm{ml}$ sulphuric acid solution to remove any contamination, and surface oxides of $\mathrm{Cu}$. Then, the $\mathrm{Cu}$ plates were activated in a $0.1 \mathrm{~g}$ palladium chloride solution. For each step, the substrate was rinsed in distilled water before moving on to the next step as illustrated in Figure 1.

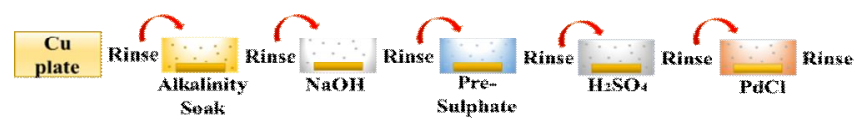

Figure 1: Steps of pre-treatment process.

Subsequently, two layers of nickel with high-P and silver were deposited on the $\mathrm{Cu}$ plate by using electroless and immersion coating processes respectively, to produced ENImAg surface finish. The next step is the investigation on the interfacial reaction of the $\mathrm{Sn}-\mathrm{xAg}(\mathrm{x}=2.5$ and $3.5 \mathrm{wt} . \%)$ solder with the ENImAg pad metallization. The sample sets are displayed schematically in Figure 2. The samples were reflowed in a furnace at $230{ }^{\circ} \mathrm{C}$ for 20 minutes. Then, the samples were repeated to proceed with double, third and fourth reflow with the same parameters. The samples were observed from both cross-sectional and top views. The samples of cross-sectional were prepared using cold mounting in epoxy resin, followed by grinding and polishing for microstructure examination. The top surface samples were uncovered by deep etching solution in order to etch away solder or Sn to reveal IMC morphology at the interface.

For the single-lap shear test, the overlap area between the substrate was filled with a solder with the dimension area of $10 \mathrm{~mm} \times 10 \mathrm{~mm}$. The shear test was conducted with a universal testing machine (UTM) with $10 \mathrm{~mm} / \mathrm{min}$ speed. Then, all samples were observed by both optical microscopy (OM) and scanning electron microscopy (SEM). Also, energy dispersive $\mathrm{x}$-ray (EDX) analysis was employed to identify the type and composition of IMC. 


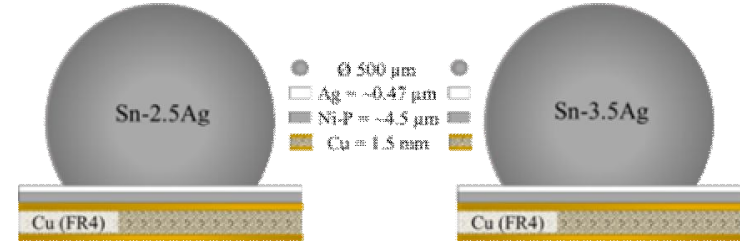

Figure 2: Illustration of sample preparation for reflow soldering.

\section{RESULTS AND DISCUSSIONS}

The $\mathrm{Sn}-\mathrm{Ag} / \mathrm{ENImAg}$ for the top and cross-sectioned view after reflow is displayed in Figure 3. Figure 4 displays the illustrations of IMC layers. Meanwhile, the multiple reflows samples of $\mathrm{Sn}-\mathrm{Ag} / \mathrm{ENImAg}$ for the top surface and cross-sectioned views are presented in Figure 5 and Figure 6. Lastly, Figure 7 and Figure 8 show the bar chart of IMC growth and fracture surface of $\mathrm{Sn}-\mathrm{xAg} / \mathrm{ENImAg}$ solder joint, respectively.

\subsection{Reflow Soldering}

In this study, electroless nickel was co-deposited with high-P because of good corrosion-resistant, ductility, and low porosity. The use of different phosphorous content in the nickel solution resulted in the different characteristics of structures, physical, and mechanical properties. After electroless nickel plating with a temperature setting of $90 \square$ at 1 hour, the layer of Ni-P was coated on $\mathrm{Cu}$ substrate, followed by immersion silver plating with a parameter used in $45 \square$ for 8 minutes. There is no IMC layer formation after plating. This is because the phosphorous was trapped between $\mathrm{Ni}$ atoms in a random fashion. The IMC formation happened during soldering.

Figure 3 shows the SEM images of the IMC morphologies for both top and cross-sectioned views, which were between $\mathrm{Sn}-\mathrm{Ag}$ solder with different mass percentages of Ag namely Sn-2.5Ag and Sn-3.5Ag solder alloy and ENImAg substrates after reflow soldering. The EDX analysis showed that, the initial IMCs were spotted an irregular layer of $\mathrm{Ni}_{3} \mathrm{Sn}_{4}$ IMC with the approximate composition at 35 at.\% $\mathrm{Ni}$ and 58.53 at.\% Sn and this consistent with the previous research. Three different morphologies can be observed: (i) blocky-like, (ii) rod-like and (iii) needle-like phases. With EDX, the blocky-like and rod-like were found to correspond to $\mathrm{Ni}_{3} \mathrm{Sn}_{4}$, and also a rod-like $\mathrm{Ag}_{3} \mathrm{Sn}$ phase as presented in Figure 3(a, b). Meanwhile, Figure 3(c, d) be visible the blocky-like and needle-like of $\mathrm{Ni}_{3} \mathrm{Sn}_{4}$ morphologies. Also, the needle-like phase of $\mathrm{Ag}_{3} \mathrm{Sn}$ was detected at the interface and close to the $\mathrm{Ni}_{3} \mathrm{Sn}_{4}$. The phase consists of 55.14 at.\% Ag and 31.55 at.\% $\mathrm{Sn}$, which indicated $\mathrm{Ag}_{3} \mathrm{Sn}$.

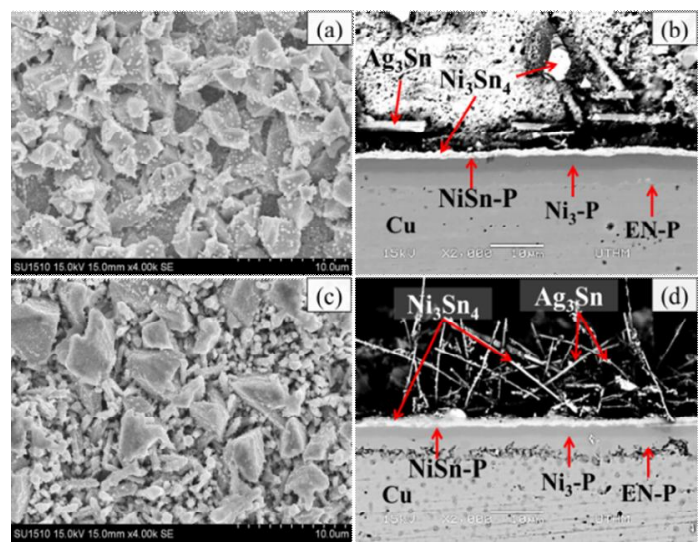

Figure 3: SEM-EDX images on top and cross-sectioned view as-reflowed; (a, b) Sn-2.5Ag/ENImAg and (c, d) Sn-3.5Ag/ENImAg.

From the observation, the Ag layer not formed at the interface because it had dissolved very rapidly in the molten solder. Then, go away from $\mathrm{Cu} / \mathrm{Ni}$ layer prone to the molten solder and the final wetting of the $\mathrm{Sn}-\mathrm{Ag}$ solder is always on the nickel surface. Also, the presence of the $\mathrm{Ag}$ layer and $\mathrm{Ag}$ content in the solder does not detect in $\mathrm{Ni}_{3} \mathrm{Sn}_{4}$ IMC. The results also revealed that a $\mathrm{Ni}_{3} \mathrm{P}$ (dark layer) formed between $\mathrm{Ni}_{3} \mathrm{Sn}_{4}$ and EN-P (light grey) layer. This layer contained approximately 28.32 at.\% $\mathrm{P}$ or 13.16 wt.\% $\mathrm{P}$ from compositional analysis, which is very close to the stoichiometry of the $\mathrm{Ni}_{3} \mathrm{P}$ phase ( $15 \mathrm{wt} . \% \mathrm{P}$ ). Therefore, this dark layer is identified as $\mathrm{Ni}_{3} \mathrm{P}$ phase, as found in previous research [45]. The thickness of $\mathrm{Ni}_{3} \mathrm{P}$ layer is approximately $2.45 \mu \mathrm{m}$ and $2.3 \mu \mathrm{m}$ for both $\mathrm{Sn}-2.5 \mathrm{Ag} / \mathrm{ENImAg}$ and Sn-3.5Ag/ENImAg, respectively.

According to Yoon and Jung [28], the thickness of $\mathrm{Ni}_{3} \mathrm{P}$ is about half of the original Ni-P. In this research, the thickness of EN layer is range $4.5 \mu \mathrm{m} \sim 6 \mu \mathrm{m}$. This result similar reported by Yoon and Jung [28]. Underneath the $\mathrm{Ni}_{3} \mathrm{Sn}_{4}$ layer, a thin and uneven layer IMC was observed and this is might be NiSn-P IMC layer as illustrated in Figure 4. NiSn-P layer commonly formed between $\mathrm{Ni}_{3} \mathrm{Sn}_{4}$ and $\mathrm{Ni}_{3} \mathrm{P}$ during a liquid-state reaction. However, this layer was tough to analyse and measure by SEM/EDX due to its thin thickness. Based on the investigation from a previous study [29], they used transmission electron microscopy (TEM) to measure the NiSn-P layer. The result show that the NiSn-P was found to contain a mixture of $\mathrm{Ni}_{2} \mathrm{Sn}-\mathrm{P}$ and $\mathrm{Ni}$. Thus, we have declared it as the $\mathrm{Ni}_{2} \mathrm{Sn}-\mathrm{P}$ IMC.

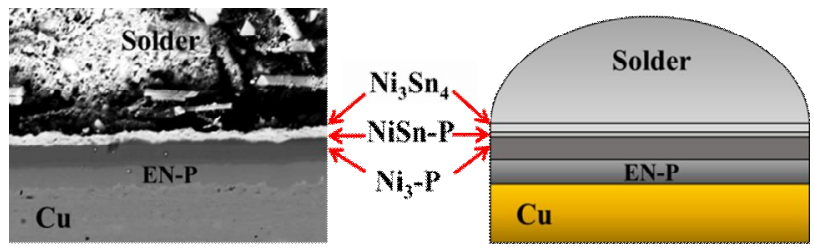

Figure 4: The position of IMC layers for $\mathrm{SnAg} / \mathrm{ENImAg}$. 


\subsection{Multiple Reflows Soldering}

After up to fourth reflows, three types of IMC were observed at the interface as shown in Figure 5. The compositions of $\mathrm{Ni}_{3} \mathrm{Sn}_{4}, \mathrm{NiSn}-\mathrm{P}, \mathrm{Ag}_{3} \mathrm{Sn}$, and $\mathrm{Ni}_{3} \mathrm{P}$ layer were found to be similar to that of Figure 3. It can be observed that two layers of $\mathrm{Ni}_{3} \mathrm{Sn}_{4}$ and NiSn-P grew thicker during multiple reflows. In Figure 5(a), rod, blocky and needle-shaped intermetallic grains were identified as $\mathrm{Ni}_{3} \mathrm{Sn}_{4}$ and $\mathrm{Ag}_{3} \mathrm{Sn}$, respectively after the second reflow. Due to increasing of IMC thickness, a planar of NiSn-P IMC can be examine and consists of 21.38 at. $\% \mathrm{Sn}, 21.38$ at. $\% \mathrm{Ni}$, and 5.82 at.\% $\mathrm{Cu}$. The existing of a small quantity of $\mathrm{Cu}$ (up to 5 at.\%) at NiSn-P indicated as $\mathrm{Ni}_{2} \mathrm{Sn}-\mathrm{P}$. Therefore, it proved that a thin and uneven layer that formed at $\mathrm{Ni}_{3} \mathrm{Sn}_{4} / \mathrm{Ni}_{3} \mathrm{P}$ as-reflowed known as $\mathrm{Ni}_{2} \mathrm{Sn}-\mathrm{P}$. This layer not only grew during a liquid-state reaction, but can grow even during solid-state reaction [46].

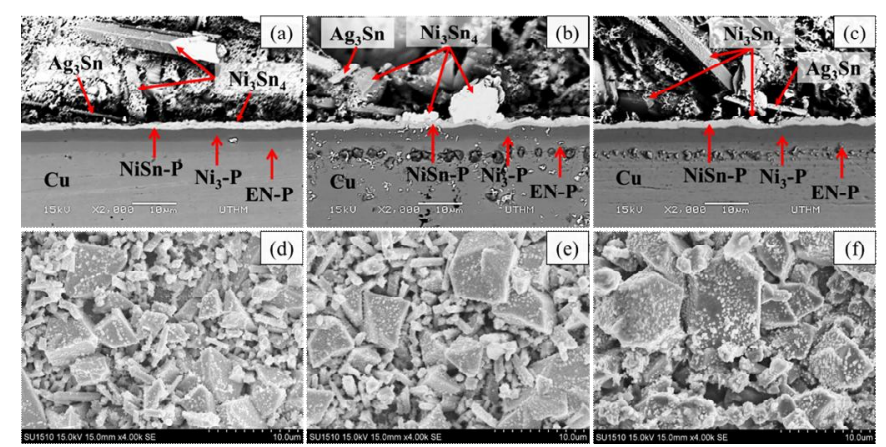

Figure 5: SEM-EDX images of cross-sectioned and top view for Sn-2.5Ag/ENImAg; (a, d) second, (b, e) third, and (c, f) fourth reflows.

Figure 5(b) and Figure 5(c) present the BSE-SEM microstructure for the third and fourth reflow. $\mathrm{Ni}_{3} \mathrm{Sn}_{4}$ IMC in the $\mathrm{Sn}-2.5 \mathrm{Ag} / \mathrm{ENImAg}$ solder alloy was mainly blocky-like and rod-like. The $\mathrm{Ag}_{3}$ sn phase formed as plate-like. Regarding to NiSn-P layer, the layer has been identified in planar and irregular shaped at the solder joint. It has been found that the NiSn-P layer became thicker with increasing reflow time. This situation can be related to the diffusion of $\mathrm{Sn}$ along with the $\mathrm{Ni}_{3} \mathrm{P}$ layer.

In the beginning, $\mathrm{Sn}$ in the solder reacted with Ni-P layer to form $\mathrm{Ni}_{3} \mathrm{Sn}_{4}$ IMC and a thin layer of NiSn-P. However, during the samples exposed to multiple reflows, all of the $\mathrm{Ni}-\mathrm{P}$ has been reacted. Thus, an insufficient of $\mathrm{Ni}$ atoms from EN-P causes Sn from solder more reacting with $\mathrm{Ni}_{3} \mathrm{P}$ and resulted in thicker IMC of NiSn-P. In contrast, $\mathrm{Ni}_{3} \mathrm{~S}_{4}$ layer was found to become thinner with increasing reflow time. This layer became thinner might be due to the reduction of the amount $\mathrm{Ni}$ atoms from EN-P. But, the growth of $\mathrm{Ni}_{3} \mathrm{~S}_{4}$ is still continuing in as much as $\mathrm{Ni}$ is sufficient from the underlying EN-P layer.

Figure 6 shows the BSE-SEM image of the Sn-3.5Ag/ENImAg interface, up to fourth reflows. These images showing the growth of $\mathrm{Ni}_{3} \mathrm{Sn}_{4}$ and NiSn-P. From the image in Figure 6(a), the large blocky shape $\left(\mathrm{Ni}_{3} \mathrm{Sn}_{4}\right)$ and rod-like $\left(\mathrm{Ag}_{3} \mathrm{Sn}\right)$ are observed in the solder bulk, and to be similar to that of Figure 6(b). However, the non-uniform layer of $\mathrm{Ni}_{3} \mathrm{P}_{4}$ and NiSn-P was observed in Figure 6 (a). But, in Figure 6(b) $\mathrm{Ni}_{3} \mathrm{Sn}_{4}$ layer becomes flatter and thinner with increasing NiSn-P layer. Obviously, there is no bigger shape of $\mathrm{Ni}_{3} \mathrm{Sn}_{4}$ microstructure (blocky-like) at the solder bulk, Figure 6(c). But the IMC layer is thicker than the second and third reflows. In terms of grain size, it was identified that the grain size became bigger and compact with reflows time as can be compared in Figure 5(d, e and f) and Figure 6(d, e and f). Also, their morphologies shape for $\mathrm{Sn}-2.5 \mathrm{Ag} / \mathrm{ENImAg}$ is not substantially different from sn-3.5Ag/ENImAg solder joints.

Moreover, large $\mathrm{Ag}_{3} \mathrm{Sn}$ was not only detected at solder bulk and interface onto or next $\mathrm{Ni}_{3} \mathrm{Sn}_{4} \mathrm{IMC}$, small particles or nano-particles of $\mathrm{Ag}_{3} \mathrm{Sn}$ were also observed on top surface view with white particles as can be seen in Figures 3, 5 and 6, and its grain sizes did not increase with multiple reflows soldering. The formation of $\mathrm{Ag}_{3} \mathrm{Sn}$ commonly can affect the

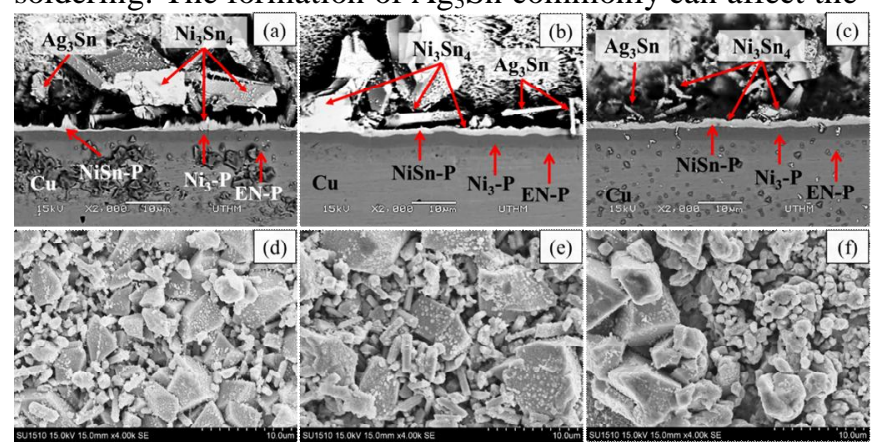

Figure 6: SEM-EDX images of cross-sectioned and top view for $\mathrm{Sn}-3.5 \mathrm{Ag} / \mathrm{ENImAg}$; (a, d) second, (b, e) third and (c, f) fourth reflows.

solder joint performance, which is it can cause crack propagation and resulted in poor performance of solder joint.

\subsection{Solder Joint Reliability}

Figure 7 presents the graph of IMC thickness against the reflow time with different mass percentages of $\mathrm{Ag}$ in the Sn-Ag solder on the IMC growth., After reflow soldering, $\mathrm{Ni}_{3} \mathrm{Sn}_{4}$ and a very thin layer of NiSn-P layer were detected as mentioned before. Meantime, NiSn-P grew rapidly during exposure to multiple reflows due to the limited diffusion of the growth layer and also related to insufficient $\mathrm{Ni}$ atoms in the EN-P layer during soldering. As reflow time increased, the thickness of both $\mathrm{Sn}-2.5 \mathrm{Ag} / \mathrm{ENImAg}$ and sn-3.5Ag/ENImAg IMC layer increased.

As a comparison, the interfacial of $\mathrm{Sn}-2.5 \mathrm{Ag} / \mathrm{ENImAg}$ with that of the sn-3.5Ag/ENImAg solder joints, a thin layer was observed as can be seen in Figure 7. As reflowed, the results revealed that the thickness value for $\mathrm{Sn}-2.5 \mathrm{Ag} / \mathrm{ENImAg}$ was $1.62 \mu \mathrm{m}$. The value was larger than to the thickness value of Sn-3.5Ag/ENImAg, which was $1.53 \mu \mathrm{m}$. The IMC thickness 
that formed in $\mathrm{Sn}-2.5 \mathrm{Ag} / \mathrm{ENImAg}$ was not much different from those that formed in the $\mathrm{Sn}-3.5 \mathrm{Ag} / \mathrm{ENImAg}$. It was recorded that the difference value between both layers was approximately $0.09 \mu \mathrm{m}$. The value of IMC thickness for the second, third and fourth reflow has been listed in Table 1. From the observation, the difference in thickness is remarkably consistent for the second and third reflow, which is the IMC thickness of $\mathrm{Sn} 2.5 \mathrm{Ag} / \mathrm{ENImAg}$ is thicker than Sn-3.5Ag/ENImAg. These results seem to be consistent with [47] which found adding more $\mathrm{Ag}$ element in solder, will make the grains size and IMC thickness became smaller and thinner at the interface.

Subsequently, in the Sn-3.5Ag/ENImAg solder joint, the IMC thickness for the fourth reflow was different from the Sn2.5Ag/ENImAg IMC formation that form in first, second and third reflow. During fourth reflow, the IMC is thicker than that of $\mathrm{Sn} 2.5 \mathrm{Ag} / \mathrm{ENImAg}$. This finding might be due to the stability of temperature and solid diffusion during IMC growth. However, the different mass percentages of the $\mathrm{Ag}$ element on Sn-Ag solder are not substantially different in terms of grains size and IMC thickness between $\mathrm{Sn} 2.5 \mathrm{Ag} / \mathrm{ENImAg}$ and Sn-3.5Ag/ENImAg. For both solder joints has a marginal difference of thickness at range $0.09 \mu \mathrm{m}$ ( $1^{\text {st }}$ reflow $), 0.18 \mu \mathrm{m}$ ( $2^{\text {nd }}$ reflow $), 0.06 \mu \mathrm{m}$ ( $3^{\text {rd }}$ reflow $)$ and $0.17 \mu \mathrm{m}\left(4^{\text {th }}\right.$ reflow $)$. In contrast, the previous report states that the amount of Ag to Sn-rich solders not influence the thickness of IMC [48].

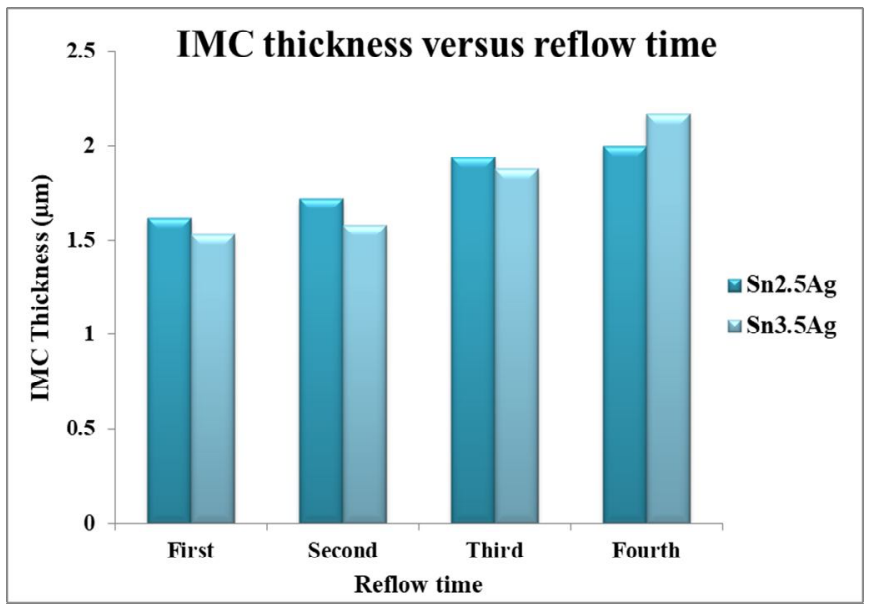

Figure 7: The Effect of Ag percentages on the growth of IMC.

Table 1: Total intermetallic thickness value of $\mathrm{Sn}-\mathrm{Ag} / \mathrm{ENImAg}$ solders joints

\begin{tabular}{|c|c|c|c|c|c|c|}
\hline \multirow[t]{3}{*}{$\begin{array}{l}\text { Reflow } \\
\text { time }\end{array}$} & \multicolumn{2}{|c|}{$\begin{array}{l}\text { Sn2.5Ag/ } \\
\text { ENImAg }\end{array}$} & \multirow[t]{3}{*}{$\begin{array}{l}\text { Total } \\
\text { IMC }\end{array}$} & \multicolumn{2}{|c|}{$\begin{array}{l}\text { Sn3.5Ag/ } \\
\text { ENImAg }\end{array}$} & \multirow[t]{3}{*}{$\begin{array}{l}\text { Total } \\
\text { IMC }\end{array}$} \\
\hline & \multicolumn{2}{|c|}{ Thickness $(\mu \mathrm{m})$} & & Thickn & $s \mathrm{~s}(\mu \mathrm{m})$ & \\
\hline & $\mathrm{Ni}_{3} \mathrm{Sn}_{4}$ & NiSn-P & & $\mathrm{Ni}_{3} \mathrm{Sn}_{4}$ & NiSn-P & \\
\hline First & 1.62 & - & 1.62 & 1.53 & - & 1.53 \\
\hline Second & 0.73 & 1.03 & 1.76 & 0.96 & 0.62 & 1.58 \\
\hline Third & 0.54 & 1.4 & 1.94 & 0.73 & 1.15 & 1.88 \\
\hline Fourth & 0.41 & 1.59 & 2 & 0.87 & 1.3 & 2.17 \\
\hline
\end{tabular}

From the explanations above, this observation can be proved with solder joint strength. Figure 8 presents the SEM images of single-lap shear strength results obtained for Sn-2.5Ag/ENImAg and sn-3.5Ag/ENImAg after reflow soldering. The results obtained for both solder joints were 160.1 MPa and 166.45 MPa, respectively, with a margin of difference of around $6.35 \mathrm{MPa}$. There is no much difference value of strength between them, but the $3.5 \mathrm{Ag} / \mathrm{ENImAg}$ solder joint has higher shear strength than Sn-2.5Ag/ENImAg solder joint despite having the thinner IMC layer. The thicker IMC layer may lead to a coarsening of the solder microstructure and crack propagation due to characteristic of IMC is brittle. Therefore, the higher value of shear strength observed in the $3.5 \mathrm{Ag} / \mathrm{ENImAg}$ solder joint can reasonably be attributed to a thinner IMC layer compared to $\mathrm{Sn}-2.5 \mathrm{Ag} / \mathrm{ENImAg}$.

The fracture surface of the $\mathrm{Sn}-\mathrm{Ag} / \mathrm{ENImAg}$ solder joint can provide different deformation mechanisms, where it depends on the area of their failure. Based on Figure 8( $a$ and $b)$, the fracture surface happened within the $\mathrm{Sn}-2.5 \mathrm{Ag}$ solder matrix. However, it was also found a small size cup/cone-like fracture, which is referred to as a near brittle fracture (IMC area). With the addition of a $3.5 \mathrm{wt} . \%$ in Sn-rich solder, the size of the cup/cone fracture reduced. The fracture surface shows a partial cleavage and dimpled fractured as presented in Figure 8(c and d). The fracture area happened at $\mathrm{Sn}-3.5 \mathrm{Ag}$ solder matrix and referred to as a ductile fracture. It has been observed that $\mathrm{Sn}-2.5 \mathrm{Ag} / \mathrm{ENImAg}$ solder joint has more to brittle fracture rather than ductile fracture, Hence, the solder joint strength is smaller than that of $3.5 \mathrm{Ag} / \mathrm{ENImAg}$, where its more to ductile fracture. In addition, this finding also suggests that the $3.5 \mathrm{Ag} / \mathrm{ENImAg}$ solder matrix is weaker than the IMC layer between the Sn-Ag solder and ENImAg substrate.

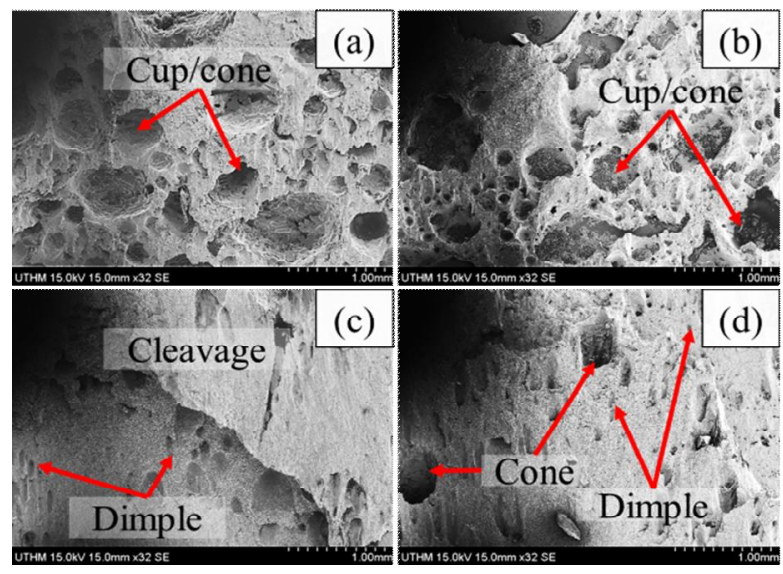

Figure 8: Fracture surface of $\mathrm{Sn}-\mathrm{Ag} / \mathrm{ENImAg}$ solder joint as-reflowed; (a, b) Sn-2.5Ag/ENImAg and (c, d) Sn-3.5Ag/ENImAg.

Table 2 shows the total IMC of Sn-Ag solder alloy and with/without surface finish between the current study and previous studies. It clearly is seen that the IMC was thinner with an ENImAg surface finish than that of without surface finish (bare $\mathrm{Cu}$ ). The difference in IMC thickness between them was approximately $1.28 \mu \mathrm{m}(\mathrm{Sn}-2.5 \mathrm{Ag})$ and $0.17 \mu \mathrm{m}$ $(\mathrm{Sn}-3.5 \mathrm{Ag})$. From the comparison, it can be verified that 
ENImAg has good solderability rather than bare $\mathrm{Cu}$ and has outstanding performance on the board. One of the most significant findings to emerge from this study is that the different amount of the amount of $\mathrm{Ag}$ in the $\mathrm{Sn}-\mathrm{Ag}$ solder alloy does not change too much in terms of grains size, thickness and solder's joint strength. Besides, the usage of ENImAg surface finish on the $\mathrm{Cu}$ plate can slow down the IMC growth, as well as enhance the reliability of the solder joint.

Table 2: The different of IMC thickness between $\mathrm{SnAg} / \mathrm{ENImAg}$ and $\mathrm{SnAg} / \mathrm{Cu}$ substrate after reflow soldering.

\begin{tabular}{|c|c|c|c|}
\hline Solder & Surface finish & Thickness $(\mu \mathrm{m})$ & References \\
\hline \multirow{2}{*}{$\begin{array}{c}\text { Sn-2.5A } \\
\mathrm{g}\end{array}$} & ENImAg & 1.62 & Current \\
\cline { 2 - 4 } & Bare $\mathrm{Cu}$ & 2.9 & {$[49]$} \\
\hline \multirow{2}{*}{$\begin{array}{c}\text { Sn-3.5A } \\
\mathrm{g}\end{array}$} & ENImAg & 1.53 & Current \\
\cline { 2 - 4 } & Bare $\mathrm{Cu}$ & 1.7 & {$[48]$} \\
\hline
\end{tabular}

\section{CONCLUSION}

The growths of the IMC layer, interfacial microstructures and fracture surfaces of $\mathrm{Sn}-\mathrm{xAg} / \mathrm{ENImAg}$ were explored. The findings showed that a higher mass percentage of an $\mathrm{Ag}$ element in Sn-Ag solders improved solder joint performance. Besides, the surface finish of ENImAg could control the IMC growth at the interface during reflow soldering. The conclusions are summarized below.

After reflow and multiple reflows soldering, the IMCs of $\mathrm{Ni}_{3} \mathrm{Sn}_{4}$ and NiSn-P were observed at the $\mathrm{Sn}-\mathrm{xAg} / \mathrm{ENImAg}$ interface. $\mathrm{Ag}_{3} \mathrm{Sn}$ was also observed at the interface and bulk solder. Besides, IMC layer and grain sizes get thicker and larger with the increasing number of reflow cycles. For the Sn-3.5Ag/ENImAg solder joint, it has resulted in a thinner IMC layer and smaller grain sizes compared to Sn-2.5Ag/ENImAg. Furthermore, the shear strength of the solder joint decreased with the mass percentage of the $\mathrm{Ag}$ element in the $\mathrm{Sn}-\mathrm{Ag}$ solder alloy which is the fracture surface that happened at the solder matrix and also near the brittle area.

These findings enhance the understanding of the IMC formation and growth at $\mathrm{Sn}-\mathrm{xAg} / \mathrm{ENImAg}$ interface, which is the reliability of solder joints affected by reflow condition, mass percentages of an element in solder, as well as surface finish. This study also can help the manufacturers in the electronics industry to achieve the positive features of the surface finish for the PCB, especially of the ENImAg surface finish.

\section{ACKNOWLEDGEMENT}

The authors would like to thank the Ministry of Education Malaysia for supporting this research under Fundamental Research Grant Scheme Vot No. FRGS/1/2019/TK03/UTHM/02/6, Postgraduate Research
Grant Scheme (Vot H363), and facilities provided by faculty of Mechanical and Manufacturing Engineering, Universiti Tun Hussein Onn Malaysia.

\section{REFERENCES}

[1] S. H. Kim and S. Yang. Low melting temperature solder materials for use in flexible microelectronic packaging applications, Recent Progress in Soldering Materials, pp. 7-37, Nov. 2017.

[2] D. R. Frear and P. T. Vianco. Intermetallic growth and mechanical behavior of low and high melting temperature solder alloys, Metall. Mater. Trans. A, vol. 25, no. 7, pp. 1509-1523, July 1994.

[3] O. M. Abdelhadi and L. Ladani. IMC growth of Sn-3 . 5Ag / Cu system : Combined chemical reaction and diffusion mechanisms, J. Alloys Compd., vol. 537, pp. 87-99, May 2012.

[4] H. R. Kotadia, P. D. Howes, and S. H. Mannan. A review: On the development of low melting temperature Pb-free solders, Microelectron. Reliab., vol. 54, no. 6-7, pp. 1253-1273, Apr. 2014.

[5] E. E. M. Noor, N. M. Sharif, C. K. Yew, T. Ariga, A. B. Ismail, and $Z$. Hussain. Wettability and strength of In-Bi-Sn lead-free solder alloy on copper substrate, J. Alloys Compd., vol. 507, no. 1, pp. 290-296, Aug. 2010.

[6] M. E. Loomans, S. Vaynman, G. Ghosh, and M. E. Fine. Investigation of multi-component lead-free solders, J. Electron. Mater., vol. 23, no. 8, pp. 741-746, Mar. 1994.

[7] A. Sharif, Y. C. Chan, and R. A. Islam. Effect of volume in interfacial reaction between eutectic $\mathrm{Sn}-\mathrm{Pb}$ solder and $\mathrm{Cu}$ metallization in microelectronic packaging, Mater. Sci. Eng. B, vol. 106, no. 2, pp. 120-125, Sept. 2004.

[8] J. W. Yoon, S. W. Kim, and S. B. Jung. IMC morphology, interfacial reaction and joint reliability of $\mathrm{Pb}$-free $\mathrm{Sn}-\mathrm{Ag}-\mathrm{Cu}$ solder on electrolytic Ni BGA substrate, J. Alloys Compd., vol. 392, no. 1-2, pp. 247-252, Nov. 2005.

[9] D. R. Frear. Issues related to the implementation of Pb-free electronic solders in consumer electronics, J. Mater. Sci. Mater. Electron., vol. 18, pp. 319-330, Sept. 2007.

[10] H. T. Ma, J. Wang, L. Qu, N. Zhao, and A. Kunwar. A study on the physical properties and interfacial reactions with $\mathrm{Cu}$ substrate of rapidly solidified Sn-3.5Ag lead-free solder, J. Electron. Mater., vol. 42, no. 8, pp. 2686-2695, June 2013.

[11] W. R. Osório, L. C. Peixoto, L. R. Garcia, N. Mangelinck-Noël, and A. Garcia. Microstructure and mechanical properties of $\mathrm{Sn}-\mathrm{Bi}, \mathrm{Sn}-\mathrm{Ag}$ and Sn-Zn lead-free solder alloys, J. Alloys Compd., vol. 572, pp. 97-106, Apr. 2013.

[12] F. Wang, Y. Huang, Z. Zhang, and C. Yan. Interfacial reaction and mechanical properties of 
Sn-Bi solder joints, Materials (Basel)., vol. 10, no. 8, Aug. 2017.

[13] A. Mulugeta and S. Guna. Lead-free Solders in Microelectronic, Mater. Sci. Eng. R Reports, vol. 27, no. 5, pp. 95-141, Feb. 2000.

[14] H. T. Ma, L. Qu, M. L. Huang, L. Y. Gu, N. Zhao, and $\mathrm{L}$. Wang. In-situ study on growth behavior of $\mathrm{Ag} 3$ $\mathrm{Sn}$ in $\mathrm{Sn}-3.5 \mathrm{Ag} / \mathrm{Cu}$ soldering reaction by synchrotron radiation real-time imaging technology, J. Alloys Compd., vol. 537, pp. 286-290, May 2012.

[15] K. Y. Lee, M. Li, D. R. Olsen, W. T. Chen, B. T. C. Tan, and S. Mhaisalkar. Microstructure, joint strength and failure mechanism of $\mathrm{Sn}-\mathrm{Ag}$, Sn-Ag-Cu versus Sn-Pb-Ag solders in BGA packages, in Proc. 51st Electronic Components and Technology Conf. (Cat. No. O1CH37220), 2001, pp. 478-485.

[16] A. Sharif and Y. C. Chan. Dissolution kinetics of BGA Sn-Pb and Sn-Ag solders with Cu substrates during reflow, Mater. Sci. Eng. B Solid-State Mater. Adv. Technol., vol. 106, no. 2, pp. 126-131, Sept. 2004.

[17] K. N. Tu and K. Zeng. Tin-lead (SnPb) solder reaction in flip chip technology, Mater. Sci. Eng. R Reports, vol. 34, no. 1, pp. 1-58, Jan. 2001.

[18] Y. Lin and K. Lin. The early stage dissolution of Ni and the nucleation of $\mathrm{Ni}$ - Sn intermetallic compound at the interface during the soldering of Sn - 3 . 5Ag on a Ni substrate, J. Appl. Phys., vol. 108, no. 6, pp. 063536 (1-4), Sept. 2010.

[19] J. Hajdu. Surface preparation for electroless nickel plating, Electroless Plating: Fundamentals and Applictions, 1990, pp. 193-206.

[20] J. Sudagar, J. Lian, and W. Sha. Electroless nickel, alloy, composite and nano coatings-A critical review, J. Alloys Compd., vol. 571, pp. 183-204, Mar. 2013.

[21] S. Sapkal, A. Bhagwat, D. Bendrikar-shinde, Z. Vadhwania, R. Gondil, and R. Waikar. Parametric analysis of electroless nickel plating - A review, in Proc. of the National Conf. on, Modeling, Optimization and control (NCMOC), 2015, pp. 1-5.

[22] C. A. Loto. Electroless nickel plating - A review, Silicon, vol. 8, no. 2, pp. 177-186, Jan. 2016.

[23] K. G. Keong, W. Sha, and S. Malinov. Crystallization and phase transformation behaviour of electroless nickel-phosphorus deposits with low and medium phosphorus contents under continuous heating, J. Mater. Sci., vol. 37, no. 20, pp. 4445-4450, Apr. 2002.

[24] Z. Guo, K. G. Keong, and W. Sha. Crystallisation and phase transformation behaviour of electroless nickel phosphorus platings during continuous heating, J. Alloys Compd., vol. 358, no. 1-2, pp. 112-119, Jan. 2003.

[25] J. Sudagar, J. Lian, and W. Sha. Electroless nickel, alloy, composite and nano coatings-A critical review, J. Alloys Compd., vol. 571, pp. 183-204, Mar. 013.

[26] P. Liu, P. Yao, and J. Liu. Effects of multiple reflows on interfacial reaction and shear strength of $\mathrm{SnAgCu}$ and $\mathrm{SnPb}$ solder joints with different PCB surface finishes, J. Alloys Compd., vol. 470, no. 1-2, pp. 188-194, May 2009.

[27] Y. D. Lu, X. Q. He, Y. F. En, X. Wang, and Z. Q. Zhuang. Polarity effect of electromigration on intermetallic compound formation in $\mathrm{SnPb}$ solder joints, Acta Mater., vol. 57, no. 8, pp. 2560-2566, Mar. 2009.

[28] J.-W. Yoon and S.-B. Jung. Growth kinetics of Ni3Sn4 and Ni3P layer between $\mathrm{Sn}-3.5$ Ag solder and electroless Ni-P substrate, J. Alloys Compd., vol. 376, no. 1-2, pp. 105-110, Aug. 2004.

[29] A. Kumar and Z. Chen. Interdependent intermetallic compound growth in an electroless Ni-P / Sn-3 . 5Ag reaction couple, J. Electron. Mater., vol. 40, no. 2, pp. 213-223, Dec. 2011.

[30] Y. Yang et al., Significantly retarded interfacial reaction between an electroless $\mathrm{Ni}-\mathrm{W}-\mathrm{P}$ metallization and lead-free $\mathrm{Sn}-3$. $5 \mathrm{Ag}$ solder, $J$. Alloys Compd., vol. 565, pp. 11-16, Feb. 2013.

[31] C. S. Huang, J. H. Yeh, B. L. Young, and J. G. Duh. Phenomena of electroless Ni-P and intermetallic-compound stripping and dissolving in $\mathrm{Sn}-\mathrm{Bi}$ and $\mathrm{Sn}-\mathrm{Pb}$ solder joints with $\mathrm{Au} / \mathrm{EN} / \mathrm{Cu}$ metallization, J. Electron. Mater., vol. 31, no. 11, pp. 1230-1237, Apr. 2002.

[32] J. I. Lee, S. W. Chen, H. Y. Chang, and C. M. Chen. Reactive wetting between molten Sn-Bi and Ni substrate, J. Electron. Mater., vol. 32, no. 3, pp. 117-122, Aug. 2003.

[33] J. Wang, L. G. Zhang, H. S. Liu, L. B. Liu, and Z. P. Jin. Interfacial reaction between $\mathrm{Sn}-\mathrm{Ag}$ alloys and Ni substrate, J. Alloys Compd., vol. 455, no. 1-2, pp. 159-163, May 2008.

[34] S.-W. Fu, C.-Y. Yu, T.-K. Lee, K.-C. Liu, and J.-G. Duh. Impact crack propagation through the dual-phased $(\mathrm{Cu}, \mathrm{Ni})$ 6Sn5 layer in $\mathrm{Sn}-\mathrm{Ag}-\mathrm{Cu} / \mathrm{Ni}$ solder joints, Mater. Lett., vol. 80, pp. 103-105, Aug. 2012.

[35] H. Lee, C. Kim, C. Heo, C. Kim, J. H. Lee, and Y. $\mathrm{Kim}$. Effect of solder resist dissolution on the joint reliability of ENIG surface and $\mathbf{S n - A g - C u}$ solder, Microelectron. Reliab., vol. 87, no. April, pp. 75-80, May 2018.

[36] M. A. Rabiatul Adawiyah and O. Saliza Azlina. Comparative study on the isothermal aging of bare $\mathrm{Cu}$ and ENImAg surface finish for $\mathrm{Sn}-\mathrm{Ag}-\mathrm{Cu}$ solder joints, J. Alloys Compd., vol. 740, pp. 958-966, Jan. 2018.

[37] H. Chen, T.-T. Chou, C. Fleshman, and J.-G. Duh. Investigating the Effect of $\mathrm{Ag}$ Content on Mechanical Properties of Sn-Ag-Cu Micro-BGA 
Joints, J. Electron. Mater., vol. 48, no. 10, pp. 6866-6871, July 2019.

[38] M. He, Z. Chen, and G. Qi. Solid state interfacial reaction of $\mathrm{Sn}-37 \mathrm{~Pb}$ and $\mathrm{Sn}-3.5 \mathrm{Ag}$ solders with Ni-P under bump metallization, Acta Mater., vol. 52, no. 7, pp. 2047-2056, July 2004.

[39] H. . Hsu, Y. T. Huang, S. Y. Huang, T. C. Chang, and A. T. Wu. Evolution of the intermetallic compounds in Ni / Sn-2 . 5Ag / Ni microbumps for three-dimensional integrated circuits, J. Electron. Mater., vol. 44, no. 10, pp. 3888-3895, July 2015.

[40] D. Li, C. Liu, and P. P. Conway. Interfacial reactions between $\mathrm{Pb}$-free solders and metallised substrate surfaces, in 6th Int. Conf. on Electron. Packag. Technol., 2005, pp. 360-365.

[41] S. K. W. Seah, E. H. Wong, Y. W. Mai, R. Rajoo, and C. T. Lim. High-speed bend test method and failure prediction for drop impact reliability, in Proc. - Electron. Components and Technol. Conf., 2006, pp. 1003-1008.

[42] S. H. Kim and J. Yu. Secondary IMC formation induced by Kirkendall voiding in $\mathrm{Cu} / \mathrm{Sn}-3.5 \mathrm{Ag}$ solder joints, J. Mater. Res., vol. 25, no. 9, pp. 1854-1858, May 2010.

[43] C. Yu, Y. Yang, H. Lu, and J. M. Chen. Effects of current stressing on formation and evolution of kirkendall voids at $\mathrm{Sn}-3.5 \mathrm{Ag} / \mathrm{Cu}$ interface, $J$. Electron. Mater., vol. 39, no. 8, pp. 1309-1314, Mar. 2010.

[44] E. Long and L. Toscano. Electroless nickel/immersion silver- A new surface finish PCB applications, Met. Finish., vol. 111, no. 1, pp. 12-19, Feb. 2013.

[45] M. O. Alam, Y. C. Chan, and K. C. Hung. Reliability study of the electroless $\mathrm{Ni}-\mathrm{P}$ layer against solder alloy, Microelectron. Reliab., vol. 42, pp. 1065-1073, Feb. 2002.

[46] A. Kumar, Z. Chen, S. G. Mhaisalkar, C. C. Wong, P. S. Teo, and V. Kripesh. Effect of Ni-P thickness on solid-state interfacial reactions between $\mathrm{Sn-3.5Ag}$ solder and electroless Ni-P metallization on $\mathrm{Cu}$ substrate, Thin Solid Films, vol. 504, no. 1-2, pp. 410-415, Oct. 2006.

[47] M. G. Cho, Y. S. Park, S. K. Seo, K. W. Paik, and H. M. Lee. Effect of Ag Addition on the ripening growth of $\mathrm{Cu}_{6} \mathrm{Sn}_{5}$ grains at the interface of Sn-xAg-0.5Cu/Cu during a reflow, IEEE Trans. Components, Packag. Manuf. Technol., vol. 1, no. 12, pp. 1939-1946, Dec. 2011.

[48] D. Q. Yu and L. Wang. The growth and roughness evolution of intermetallic compounds of $\mathrm{Sn}-\mathrm{Ag}-\mathrm{Cu} / \mathrm{Cu}$ interface during soldering reaction, J. Alloys Compd., vol. 458, no. 1-2, pp. 542-547, Apr. 2008.

[49] S. Ha, J. Jang, S. Ha, J. Yoon, H. Lee, and J. Joo. Microelectronic Engineering Effect of multiple reflows on interfacial reaction and shear strength of Sn - Ag electroplated solder bumps for flip chip package, Microelectron. Eng., vol. 87, no. 3, pp. 517-521, July 2010. 